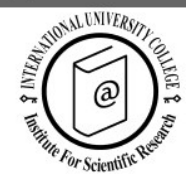

\title{
Possibilities for timeshare application in the hotel industry of the Southern Black Sea tourist area
}

\author{
Elena Klateva ${ }^{1}$
}

Received: 30/11/2015

\footnotetext{
${ }^{1}$ College of Tourism - Burgas, Park Ezero, 8000 Burgas, Bulgaria, e-mail: elena_klateva@abv.bg
}

Supervisors: Prof. Tanya Dabeva, PhD

Institution awarding the Ph. D. Degree: University of Economics - Varna, Bulgaria

Date of defence: $26 / 06 / 2015$

(C) 2016 Varna University of Management. All rights reserved

Citation: Klateva, E. (2016) Possibilities for timeshare application in the hotel industry of the Southern Black Sea tourist area. Doctoral Dissertation Summary. European Journal of Tourism Research 12, pp. 224-227

\section{Goal and objectives of the dissertation Goal}

The dissertation aims to research the timeshare development possibilities in the hotel industry of the Southern Black Sea tourist area (SBSTA) through investigating (both theoretically and empirically) timeshare hotels situated in the studied area.

\section{Objectives}

1. To theoretically analyse and define timeshare in the hotel industry and to identify its specific characteristics and types as well as the modern tendencies in the timeshare industry.

2. To clarify the role and participation of major subjects in the timeshare hotel industry, their specific characteristics and the benefits and drawbacks of timeshare for them.

3. To elaborate a specific methodology for studying the applicability of timeshare in the hotel industry of a tourist area.

4. To assess the state of timeshare in the hotel industry of SBSTA and to identify the timeshare development prospects from the perspectives of two major subjects - the timeshare developer and the timeshare interval owner.

5. To outline practical recommendations to Bulgarian hotels in SBSTA regarding the future possibilities for timeshare development along the southern Black Sea coast.

\section{Methodology}

To evaluate the possibilities for timeshare development in the researched tourist area correctly in the first place we investigated other studies on timesharing (Chi, 2009; Hahm, 2007; Betsy, 2010, Sharma et al, 2012). We concluded that they had mainly researched the strengths and weaknesses of timeshare as well as the necessary conditions favoring the timeshare purchase. Therefore, we decided to elaborate a specific methodology for studying the possibilities for timeshare application in a tourist area. Influenced by a study about the development history of timeshare worldwide at the beginning of the dissertation, we classified the factors that affect the timeshare application 
into four principal groups. The first two groups comprise the factors of external and internal environment. As regards external factors, we applied the methodology of Dabeva (2013) used in the study of the feasibility of franchising in the Bulgarian hotel industry. According to this methodology the external factors of the host destination could be divided into general and specific factors. The former are combined into two main groups economic and socio-cultural factors. The specific factors, on the other hand, are mostly connected with the conditions the Bulgarian tourism and hotel industry offers. As regards the internal factors, we studied the state and conditions of the current timeshare market in Bulgaria because we intended to investigate the timeshare application possibilities at industry rather than company level. The remaining factors that influence timeshare applicability are the direct evaluations of two main subjects in the timeshare industry - the timeshare developer and the timeshare interval owner. We targeted 3 respondent groups: the managers of timeshare hotels in SBSTA, the timeshare product owners and the potential buyers of timeshare products along the southern Black Sea coast. Data were collected in the period April-September 2014 with questionnaire and interview being the methods employed. The final dataset included 23 managers of timeshare hotels and 94 timeshare interval owners in hotels in SBSTA as well as 54 potential buyers of timeshare products in the researched area. The last data was collected using an on-line questionnaire spread in the social media FB and three of the biggest timeshare owner forums - Timeshare Talk, Timeshare Users Group and Red Week Forum. Data was further analysed with descriptive statistics such as summary, univariate analysis including central tendency (mean, median, and mode) and ANOVA.

\section{Results}

Research results show very optimistic and valuable information about the potential for timeshare development in the hotel industry of SBSTA. In the first place the evaluation of the influence of external factors is favorable. Only nine out of thirty researched external factors can be judged as unfavorable. These are the economic development in Bulgaria, level of investment, the corruption index, the level of demographic replacement, of unemployment and of the average wage, the individualism of the Bulgarian society, the seasonality in tourism and the level of variation in the hotel industry structure and of the occupancy rates. The internal factors related to the timeshare market conditions in Bulgaria also have a favorable influence on the timeshare application. Despite the lack of a well-developed timeshare market in Bulgaria, the country is evaluated as a promising timeshare destination. We registered a lot of modern timeshare practices and good quality levels of the proposed timeshare products. The study of the managerial evaluation for timeshare application possibilities in SBSTA also showed a positive attitude $(87 \%$ of respondents). Timeshare is deemed to possess great potential to improve the business climate in the tourism sector and to diversify the hotel industry in Bulgaria as well as to help overcome seasonality and low occupancy and income rates (on ayear-round basis). The owner evaluation shows the same optimistic results (85\% of respondents). Both target groups, current owners of timeshare products and potential buyers of timeshare, think that this innovative hotel product would develop successfully in SBSTA and they are willing to recommend buying timeshare in the researched area to their friends and relatives (95\%).

\section{Theoretical conclusions}

The main theoretical contribution of this research is to define the essence of timeshare, scilicet an innovative hotel product by which through contractual agreement between the developer and the buyer, the timeshare owner, his family and friends get guaranteed access to high-quality accommodation. A specific characteristic of the product is that accommodation is not hired as in a classic hotel, but it is bought in the form of vacation time intervals where the most common is the "vacation week". We also indicated the main subjects in the timeshare industry - the timeshare developer, the 
timeshare interval owner and the timeshare exchange organization (playing an essential role in the timeshare development worldwide). Furthermore, we determined the basic product elements of timeshare - the timeshare interval, the timeshare unit and the term of the timeshare agreement.

\section{Practical application of the dissertation}

The dissertation is intended to serve as a basic manual to the Bulgarian hotel developers in their decision if it would be possible and profitable for them to integrate the timeshare product in their product list and shows the current results for a specific tourist area in Bulgaria - the Southern Black Sea tourist area. It analyses all the main factors which influence the process of timeshare integration in a hotel industry of a tourist area and provides detailed studies on the best and most common practices in the worldwide timeshare industry. It also concludes that the timeshare integration in the researched area offers great prospects, especially from the perspective of the hotel developers/managers and the vacation owners. The dissertation also provides a strong basis for improvement of the current situation in the SBSTA hotel industry, which would favor the future timeshare development.

\section{Content of the dissertation}

This doctoral dissertation is structured into three chapters.

\section{Abstract of chapter one}

Chapter One is devoted to the theoretical concept of timeshare. It begins with an investigation of the timeshare development history which we classified into four main stages. The chapter provides also literature review of timeshare in the hotel industry. As a result an aggregate definition of timesharing is constructed. The chapter further delves into the characteristics of the timeshare product, where the structure of the research follows the main product elements (interval, unit, contractual term). The conclusion is that there are many variations of timeshare including fragmented time intervals, "lock-off"- units and contracts based on biennial and triennial usage. In addition to the product a research of the other three elements of the timeshare marketing $\mathrm{mix}$ - the timeshare price, promotion and distribution, is conducted.

In Chapter One special attention is paid to the main subjects in timeshare industry - the timeshare developer, owner and the exchange organization. In the first place the timeshare owner is characterized and segmented into two main groups - the US and European timeshare owners. The second subject - the timeshare developer, is also studied in depth and classified into four groups. The conclusion is that the timeshare industry is mainly represented by developers managing single timeshare objects, timeshare chains, timeshare resorts and timeshare vacation clubs. The third investigation relates to the exchange organizations, which are grouped into two main segments - global exchange distributors (representing $94 \%$ of the exchange market) and the so called "boutique" exchange companies.

Finally the chapter presents the up-to-date changes and innovations in the timeshare industry as well as the economic effect of the timeshare business.

\section{Abstract of chapter two}

Chapter Two elaborates the stages in the timeshare application possibilities methodology. In general the research shows a favorable background in the researched SBSTA as it already was highlighted in the Research Results. As far as the external factors are concerned, the specific factors seem to be more favourable than the general ones. As far as the internal factors are concerned, a detailed market research of the timeshare market in Bulgaria is conducted. The vast majority of timeshare hotels are situated on the Black Sea coast, mostly along its southern part, which motivated our choice of a tourist area. The timeshare owners are predominantly foreign nationals - mostly from Great Britain. The timeshare market in Bulgaria is characterized by low flexibility of the current product, competitive prices and low maintenance fees. Modern timeshares such as condominium hotels are widespread 
and there are already interval timeshare and vacation clubs available on the market.

The end of Chapter Two presents the studies of the managerial and of the owner evaluations for timeshare application possibilities in SBSTA. As it was noted in the Research Results, timeshare is deemed to possess great potential for further development in SBSTA. Unfortunately, apart from these results there are also some obstacles to timeshare development. From a managerial point of view, the main barriers can be seen in the external factors, more specifically in the weak legal framework for timesharing.

In the study of the owner evaluation there are also interesting results. The first target group of owners - the current owners of timeshare products, shows high satisfaction rates and the general opinion is that this innovative hotel product would have a successful development in SBSTA. Their motives for timeshare purchase are the available tourist resources, the quality of the accommodation and the low price level in SBSTA. Of the vacation product attributes service gets their highest appreciation and the managerial team's performance - the lowest, and they see one of the biggest problems with the latter in the high maintenance fees.

The second respondent group - potential buyers of timeshare in SBSTA, also shows very interesting information. The major part of them $(80 \%)$ knows or has heard of our seaside resorts and forty-one per cent would consider purchasing timeshare if they had the chance. Seventy per cent of these respondents would buy the product directly from the developer.

\section{Abstract of chapter three}

Chapter Three gives some suggestions for coping with the existing problems and obstacles to the successful timeshare application in SBSTA. They basically follow the steps in the research. One of the most important of them is that timeshare should be included in the Tourism Laws as different accommodation type. Regarding the timeshare market in Bulgaria, the most important direction for improvements is that timeshare should be introduced to Bulgarians, because we think that they are potential buyers. On the other hand, the low flexibility of the product could be surmounted through the elaboration of internal exchange programs. Also, a more intensified role of the manager in timeshares would have a positive impact. For this purpose we introduced some good practices used in the worldwide timeshare industry, including methods for dealing with conflicting owners and elaborating and operating owner loyalty and referral programs. The latter suggestions are aimed at introducing innovative information and communication technologies in the timeshares.

\section{References:}

Betsy B. (2010) Timeshare and vacation ownership executives' analysis of the industry and the future. Journal of Retail \& Leisure Property 9(1), 37-54

Chi K. (2009) Perspectives on timeshare ownership: An exploratory study of markets in China. Las Vegas: University of Nevada

Dabeva T. (2013) Hotel and restaurant franchising. Varna: Economic and Education

Hahm J. Etc (2007) State of the timeshare industry in Aruba - a call for research. Journal of Retail \& Leisure Property 6 (1), 221-229

Sharma S., Chowdhary N. (2012) Leveraging Tourism: The Business of Timeshare. South Asian Journal of Tourism Heritage 5 (1), 111-128 